Wover

\title{
TA Gestão por Valores e a Estratégia da Comunicação Organizacional: Da Pirâmide das Necessidades Humanas aos Níveis de Consciência
}

\author{
Hannah de Carvalho, Claudio Rizzo \\ PUC-SP, Brasil \\ E-mail: hannahdecarvalho@gmail.com, \\ profclaudiorizzo@hotmail.com
}

Resumo: O modelo de Gestão por valores, e a importância da comunicação organizacional aplicada como estratégia, destacam, como elemento fundamental do processo, a pessoa caracterizada pelo funcionário, consumidor e efetivamente o primeiro mercado da organização.

As formas de engajamento e comprometimento desse indivíduo estão em consonância com a missão, a visão e os valores da empresa e têm como elemento condutor e de disseminação a comunicação organizacional.

Os valores declarados e praticados pela organização são resultantes dos valores dos indivíduos que compõem o quadro de colaboradores, pois os valores pessoais são universais e transcendem contextos. Assim, na perspectiva organizacional, impactam as tomadas de decisões e definem os comportamentos.

As ansiedades e medos que os gestores possuem em relação a suprir suas necessidades não satisfeitas, sobretudo, as necessidades emocionais, é a principal fonte de disfunção que existem nas organizações, pois deles surgem os valores potencialmente limitantes, tais como: hierarquia, burocracia e foco de curto prazo, que remetem aos comportamentos contraproducentes baseados no controle, culpabilidade e manipulação.

Portanto, é através da comunicação organizacional que se pode desenvolver uma nova visão da empresa por parte dos colaboradores, tendo em vista seu caráter dialógico, que possibilita à gestão por valores, a construção e alinhamento de valores compartilhados entre os indivíduos e a organização, para elaboração de estratégias sustentáveis neste ambiente globalizado, interconectado e de sociedade em rede.

Palavras-chave: Valores; Comunicação Organizacional; Gestão 
TA Gestão por Valores e a Estratégia da Comunicação Organizacional:

Da Pirâmide das Necessidades Humanas aos Níveis de Consciência

\section{INTRODUÇÃO}

A utilização da comunicação organizacional como estratégia de gestão e em especial destacada pelo modelo de Gestão por Valores tem como elementos básicos de sua aplicação a valorização da pessoa representada pelo seu funcionário, que se constitui no consumidor efetivo e ao mesmo tempo potencial compondo o denominado primeiro mercado a ser conquistado.

Esse raciocínio também está ligado fundamentalmente no conhecimento do conceito da comunicação organizacional e sua diferença com a comunicação empresarial, bem como, o entendimento da aplicação dos seus processos de gestão baseada em valores, como estratégia organizacional no ambiente globalizado.

Outros elementos de estudo estão focados nas necessidades humanas, muito bem representadas pela Pirâmide das Necessidades Humanas de Maslow (1954), e, sobretudo, nos níveis de consciência de Barrett (2014).

O destaque dado à pessoa está literalmente ligado ao fato de que os valores e crenças da organização são resultantes dos valores e crenças dos indivíduos que nela transitam e que são parte de sua estrutura.

Compartilhados e alinhados formam no seu conjunto o que se denomina de cultura organizacional que somente poderá fluir no plano organizacional a partir do momento que se exercita uma comunicação de característica dialógica e participativa que é exatamente o conceito da comunicação organizacional.

Portanto todos esses elementos ligados de forma lógica se destacam por sua relevância nos resultados e no desenvolvimento das estratégias de alavancagem, crescimento, comunicação, e, sobretudo, na própria imagem da organização.

Nesse cenário, entende-se que a gestão por valores reforça a estratégia da comunicação organizacional devido a sua característica dialógica, interpretativa, participativa e que efetivamente atende a esse novo universo em que se transformou a arena de negócios: complexo, globalizado e conectado em redes.

\section{ALINHAMENTO DOS VALORES ORGANIZACIONAIS E PESSOAIS}

A cultura organizacional é construída através de crenças e valores compartilhados, que determinam os comportamentos dos indivíduos e impactam os resultados da organização.

O entendimento da cultura organizacional é fundamental para sustentação da estrutura, das estratégias organizacionais e alinhamento dos valores do indivíduo e dos valores da organização, pois a extensão com que o indivíduo expressa um valor através de um comportamento, exerce influência positiva ou negativa no resultado.

Os estudos sobre a importância estratégica da cultura organizacional, a partir da década de 80 , têm como base a relevância dos fatores culturais nas práticas de gestão e o impacto da cultura, como fator de diferenciação das empresas bem sucedidas.

As relações entre cultura organizacional e desempenho organizacional, resultado de pesquisas empíricas, segundo Peters e Waterman (1982), demonstram que a identificação do indivíduo com a organização, em que há uma cultura organizacional forte e coesa, são fatores que promovem o desempenho e a competitividade.

De acordo com Denison (1990), a força da cultura é preditiva de desempenho em curto prazo, pois os aspectos da cultura organizacional estão correlacionados ao desempenho da 
organização. Sendo assim, os resultados de curto e longo prazo são variáveis dependentes da cultura organizacional.

Segundo Gordon e DiTomaso (1992), uma cultura forte e um valor substantivo estão associados ao melhor desempenho da organização, pois o alinhamento do valor do indivíduo ao valor da organização gera comprometimento emocional, comunicação participativa e dialógica, permitindo que a cultura se fortaleça e agregue valor aos públicos envolvidos.

Dessa forma, a cultura de uma organização é modelo dinâmico e complexo, e pode ser aprendido, transmitido e mudado, e sua aplicação compreende os fenômenos pequenos, tais como, grupos de trabalho, assim como grandes fenômenos da cultura de uma nação ou da sociedade.

Para Schein (2001), a cultura organizacional é o modelo de pressupostos básicos inventados por determinado grupo, descoberto ou desenvolvido no processo de aprendizagem, para lidar com problemas de adaptação externa e integração interna, considerados válidos e ensinados aos demais membros como a maneira correta de perceber, pensar e sentir em relação a esses problemas.

Os valores e crenças da organização são resultantes dos valores e crenças dos indivíduos e são compartilhados, caracterizando a cultura organizacional, e impactam os comportamentos e os resultados das organizações.

Para Richard Barrett (2014), os valores são um reflexo do que o indivíduo considera ser suas necessidades, ou seja, algo que deseja conseguir, ter ou experimentar, aliviando seu sofrimento ou estresse e fazendo-o mais feliz ou alinhado com o que é.

Quando os gestores estão comprometidos somente com a satisfação dos seus interesses pessoais, o bem-estar da organização, do grupo e da comunidade a que pertencem ficam prejudicados, pois o objetivo é satisfazer suas necessidades deficientes. Dessa forma, cada decisão comunica que o foco é individual e não coletivo.

De acordo com o autor, o comportamento acima impacta de forma negativa a performance das organizações, produzindo o fenômeno da entropia cultural:

Os seres humanos são basicamente criaturas sociais: somos dependentes uns dos outros para nossa sobrevivência individual e coletiva, para o nosso progresso e sucesso. Quando alguém em grupo está mais focada nas suas necessidades ou no próprio sucesso do que nas necessidades e no sucesso do grupo, a discórdia e o conflito aparecem constantemente e ele se tornará disfuncional. A equipe jamais será capaz de atingir seu pleno potencial (BARRETT, 2014, p.15).

Entende-se por entropia cultural a quantidade de energia que é consumida na realização de trabalhos desnecessários ou improdutivos, assim como os conflitos e as frustrações que os colaboradores encontram em suas atividades diárias, impactando diretamente 0 alto desempenho, por meio de ações e comportamentos baseados nos medos dos líderes.

Quando as necessidades deficientes dos gestores não estão satisfeitas e estes apresentam comportamentos disfuncionais, tais como controle, manipulação, acusação e competição interna, a entropia cultural aumenta, e o engajamento da equipe diminui. 
TA Gestão por Valores e a Estratégia da Comunicação Organizacional:

Da Pirâmide das Necessidades Humanas aos Níveis de Consciência

Buckingham e Coffman (2011), afirmam que o aumento no engajamento dos colaboradores contribui para o aumento da produtividade, retenção de funcionários, satisfação do cliente e rentabilidade, pois o comprometimento emocional do colaborador com a missão e objetivos da organização diminui o turnover e permite o desenvolvimento do indivíduo, de maneira que agregue valor a todos os públicos envolvidos.

Segundo Barrett (2014), estudos realizados pela Gallup, empresa global de pesquisa e consultoria em gestão da performance, presente em 195 países, revelam que, em 30 anos de pesquisas detalhadas sobre comportamento econômico, organizações com funcionários altamente engajados têm taxa de crescimento 3,9\% maiores no mercado em comparação com organizações com nível baixo de engajamento dentro da mesma indústria. Portanto, o engajamento impacta diretamente a economia local através do desenvolvimento do indivíduo.

De acordo com o relatório State of the Global Workplace (2013), profissionais engajados são criativos e empreendedores e estão emocionalmente ligados à missão da organização e ao propósito de seu trabalho. Quando os funcionários não estão envolvidos e são indiferentes em relação a seus postos de trabalho e quando estão desengajados destroem uma unidade de trabalho e um negócio.

O relatório State of the Global Workplace é resultado do estudo realizado em 142 países pela Gallup, de 2011 até 2012, que consiste em dividir os profissionais em três categorias: profissionais engajados, profissionais não engajados e profissionais desengajados.

O estudo revela a importância de compreender o impacto do engajamento na economia e no desenvolvimento do indivíduo e da organização, pois funcionários engajados impulsionam a inovação e movem a organização para frente, por outro lado, funcionários ativamente desengajados se ocupam em minar o desenvolvimento do trabalho de seus colegas envolvidos em realizar.

De acordo com o relatório, $87 \%$ dos funcionários ao redor do mundo não estão engajados ou ativamente desengajados no trabalho, portanto somente $13 \%$ estão envolvidos emocionalmente e comprometidos com a criação de valor em suas organizações.

A amostra dos 142 países incluídos na pesquisa revela que $24 \%$ dos funcionários estão ativamente desengajados e $63 \%$ não engajados. O impacto da falta de engajamento recai sobre a economia e o desenvolvimento local e global. A Gallup estima que o custo com a falta de engajamento nos Estados Unidos é de \$550 bilhões por ano; na Alemanha, o custo anual é de \$186 bilhões, e no Reino Unido, o custo estimado é de \$112 bilhões por ano.

A Ásia Oriental está fora da média global de engajamento, com apenas $6 \%$ dos funcionários envolvidos com seu trabalho, resultado conduzido predominantemente pela China. De maneira que o baixo envolvimento representa um obstáculo para o crescimento continuo do país, pois os funcionários não estão emocionalmente conectados às organizações, estão somente condicionados às restrições impostas pelo governo.

Portanto, é de fundamental importância que a gestão por valores se baseie na estratégia de comunicação organizacional, para que, através da comunicação fluida, dialógica e participativa, possibilite a construção e alinhamento de valores organizacionais e do indivíduo, assim como, o comprometimento emocional com a missão da organização. 


\section{GESTÃO POR VALORES: DA PIRÂMIDE DAS NECESSIDADES AOS SETE NÍVEIS DE CONSCIÊNCIA}

O modelo dos sete níveis de consciência de Richard Barrett (2014), que tem como objetivo o mapeamento dos valores e diagnóstico da cultura organizacional, toma como base a hierarquia das necessidades proposta por Abraham Maslow (1954), e está alinhado com os sete estágios do desenvolvimento psicológico humano.

O estudo de motivação, realizado por Maslow (1954), propõe a existência de motivos relacionados às necessidades humanas, organizadas através da hierarquia de preponderância por meio do critério de gratificação, pois ao livrar o organismo de uma necessidade mais fisiológica, permite a emergência de outros objetivos mais sociais.

As necessidades foram classificadas em cinco níveis, dispostos em forma de pirâmide, conforme a figura 1. A base da pirâmide compreende as necessidades primárias, à medida que as necessidades básicas são atendidas, as necessidades relacionadas com aspectos individuais e subjetivos precisam ser supridas.

Figura 1: Pirâmide da hierarquia das necessidades de Maslow

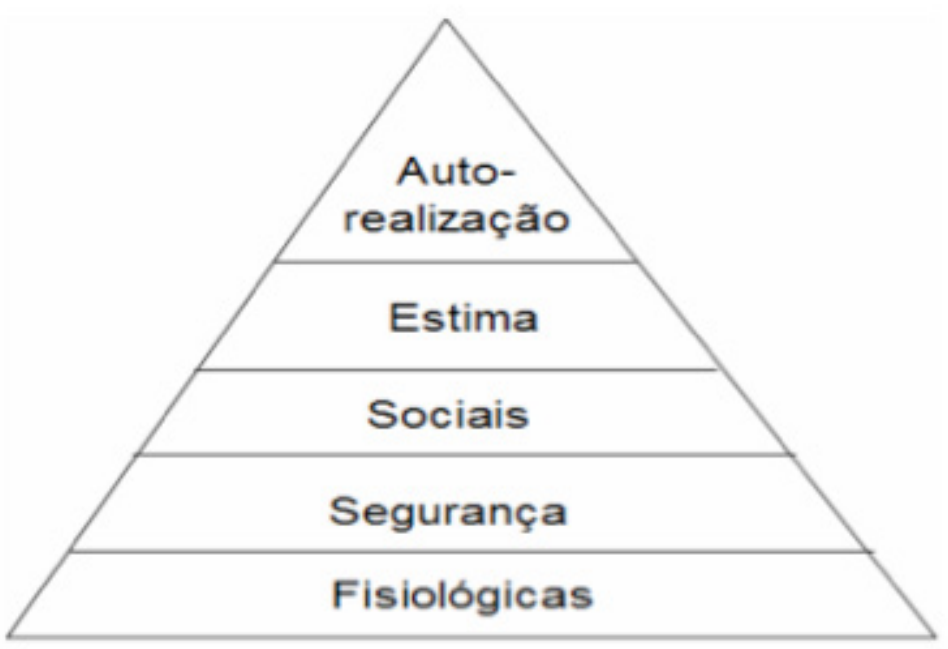

Fonte: Robbins (2002)

Robbins (2002) define cada um dos níveis de necessidades que compõe a pirâmide de Maslow da seguinte forma:

Necessidade fisiológica: Fome, sede, abrigo, sexo e outras necessidades corporais.

Necessidade de segurança: Inclui a segurança de danos físicos e emocionais.

Sociais: Incluem afeição, aceitação, amizade e pertencimento a um grupo.

Estima: Inclui fatores internos de estima, como respeito próprio, realização e autonomia; e fatores externos de estima, como status, reconhecimento e atenção.

Autorrealização: A intenção de tornar-se tudo o que a pessoa é capaz de ser; inclui crescimento, autodesenvolvimento e alcance do próprio potencial.

De acordo com Herzberg (1997) apud Robbins (2002), a pirâmide divide-se em dois níveis que se relacionam aos fatores de satisfação extrínsecos e intrínsecos da organização. 
As necessidades de nível baixo, compostas pelas necessidades fisiológicas e de segurança, se relacionam aos fatores extrínsecos, tais como, salários, benefícios, premiações e segurança financeira. O topo da pirâmide é constituído pelas necessidades de nível alto, relacionadas aos fatores intrínsecos e motivacionais, que têm como objetivo o atendimento das aspirações humanas, podendo usufruir sua potencialidade sem perder sua individualidade.

Para Barrett (2014), a evolução do modelo das necessidades de Maslow para o modelo dos sete níveis de consciência consiste na mudança do foco, pois a mente permanece focada nos níveis de consciência, que representam a necessidade do que estão experienciando.

De acordo com o autor, a crença baseada no medo em determinado nível não permitirá a satisfação de suas necessidades no seu nível de consciência, apesar de efetivamente suprido seu nível de necessidades.

Portanto, o objetivo do modelo dos sete níveis de consciência consiste em mapear, mensurar e monitorar os valores de uma organização e utilizar o resultado para redução da entropia cultural e aumento do nível de alinhamento de valores e da missão, através da transformação cultural.

Figura 2: Sete níveis da consciência pessoal.

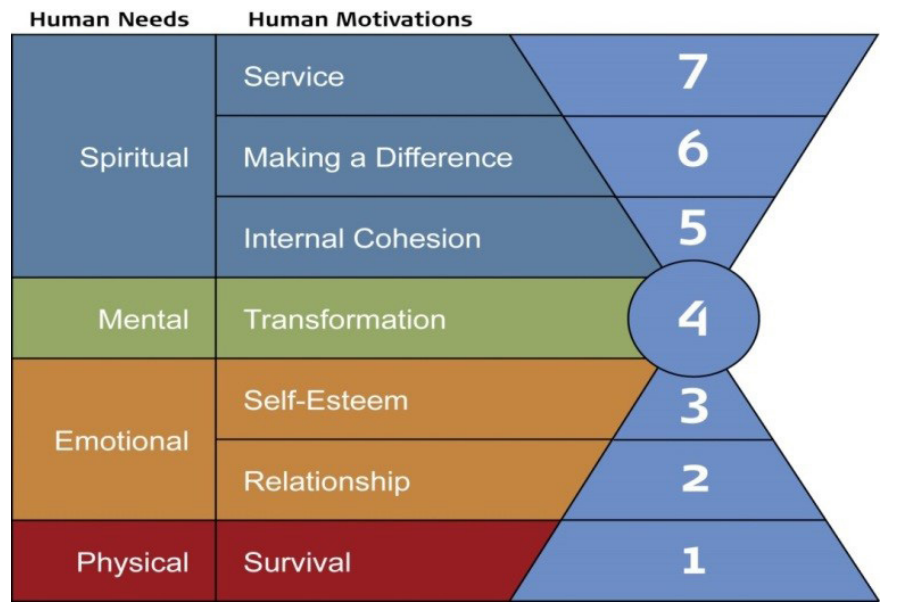

Fonte: http://www.valuescentre.com/culture/?sec=Richard Barrett_model

O foco dos primeiros três níveis de consciência está em satisfazer as necessidades do ego, pois inclui a necessidade psicológica de sobrevivência, a necessidade de segurança física (emocional e de pertencimento) e a necessidade emocional de autoestima.

O foco do quarto nível é a transformação, pois é neste estágio que os medos subconscientes e conscientes em satisfazer as necessidades físicas, de relacionamento e autoestima são supridos, e inicia-se a busca pela liberdade de tornar-se responsável pela vida. Sendo assim, a atenção central é dada às necessidades mentais.

O foco dos três níveis mais elevados de consciência está em satisfazer as necessidades da alma, através da necessidade de encontrar significado na vida, da necessidade de fazer a diferença e da necessidade de estar a serviço da humanidade, representando as necessidades espirituais. 
Quadro 1: Sete níveis de consciência pessoal

\begin{tabular}{|c|c|c|}
\hline Niveis de Consciência & Ações e necessidades & Niveis de desenvolvimento \\
\hline 7-Serviço & $\begin{array}{l}\text { Dedicar a sua vida ao serviço } \\
\text { altruísta na busca do seu propósito } \\
\text { e do bem estar da humanidade. }\end{array}$ & $\begin{array}{l}\text { Servir: Cumprir o seu destino } \\
\text { retribuindo ao mundo. }\end{array}$ \\
\hline 6-Fazer a diferença & $\begin{array}{l}\text { Realizar seu senso de propósito } \\
\text { através da colaboração com outros } \\
\text { para fazer uma diferença maior no } \\
\text { mundo do que aquela que você } \\
\text { poderia fazer por conta própria. }\end{array}$ & $\begin{array}{l}\text { Integrar: Alinhar-se com os outros } \\
\text { que compartilham o mesmo } \\
\text { propósito ou visão para criar um } \\
\text { mundo melhor. }\end{array}$ \\
\hline 5- Coesão interna & $\begin{array}{l}\text { Descobrir o seu autêntico eu e } \\
\text { encontrar significado para a sua } \\
\text { vida através do alinhamento com a } \\
\text { sua paixão e propósito e construir } \\
\text { uma visão do futuro que você quer } \\
\text { criar. }\end{array}$ & $\begin{array}{l}\text { Autorrealização: alinhar-se } \\
\text { completamente com quem você é } \\
\text { para que possa se tornar tudo o } \\
\text { que é capaz de se tornar e atingir } \\
\text { seu potencial. }\end{array}$ \\
\hline 4- Transformação & $\begin{array}{l}\text { Explorar quem você é e satisfazer } \\
\text { a sua necessidade de autonomia, } \\
\text { liberdade e independência através } \\
\text { do desenvolvimento dos seus dons } \\
\text { e talentos únicos. }\end{array}$ & $\begin{array}{l}\text { Individuação: abrir mão dos } \\
\text { aspectos do seu condicionamento } \\
\text { pessoal e cultural que não lhe } \\
\text { servem mais ou não representam } \\
\text { verdadeiramente quem você é. }\end{array}$ \\
\hline 3-Autoestima & $\begin{array}{l}\text { Satisfazer a sua necessidade de se } \\
\text { sentir bem em relação a você } \\
\text { mesmo através de conseguir } \\
\text { cuidar da sua vida, ter orgulho da } \\
\text { sua performance e sentir-se } \\
\text { reconhecido pelos outros. }\end{array}$ & $\begin{array}{l}\text { Diferenciar: Separar você mesmo } \\
\text { da multidão através do } \\
\text { aperfeiçoamento das habilidades e } \\
\text { talentos e tornar-se excelente } \\
\text { naquilo que você faz de melhor. }\end{array}$ \\
\hline 2- Relacionamento & $\begin{array}{l}\text { Satisfazer suas necessidades de } \\
\text { pertencer e sentir-se amado e } \\
\text { respeitado pela sua família, } \\
\text { amigos e colegas. }\end{array}$ & $\begin{array}{l}\text { Conformar: manter-se seguro e } \\
\text { leal à sua família, aos seus iguais e } \\
\text { cultura. }\end{array}$ \\
\hline 1- Sobrevivência & $\begin{array}{l}\text { Satisfazer suas necessidade } \\
\text { psicológicas de sobrevivência. }\end{array}$ & $\begin{array}{l}\text { Sobreviver: Ficar vivo e } \\
\text { permanecer saudável. }\end{array}$ \\
\hline
\end{tabular}

Fonte: Barrett (2014)

Segundo Barrett (2014), as organizações crescem e se desenvolvem através do domínio de suas necessidades, assim como os indivíduos. As organizações mais bem sucedidas são aquelas que desenvolvem a consciência de espectro total, ou seja, através do domínio das necessidades associadas a cada nível da consciência organizacional, respondem e se adaptam aos desafios do mercado complexo e global.

As necessidades existenciais, que constituem os sete estágios da consciência organizacional, são mostrados no quadro 2, juntamente aos desafios de desenvolvimento associados. 
Quadro 2: Sete estágios da Consciência Organizacional

\begin{tabular}{|c|c|c|}
\hline Niveis de Consciência & Ações e necessidades & Niveis de desenvolvimento \\
\hline 7-Serviço & $\begin{array}{l}\text { Criar um futuro sustentável de } \\
\text { longo prazo para a organização } \\
\text { através do aumento da } \\
\text { sustentabilidadee da humanidade } \\
\text { do planeta. }\end{array}$ & $\begin{array}{l}\text { Servindo: Salvaguardar o bem- } \\
\text { estar do planetae da sociedade } \\
\text { para gerações futuras. }\end{array}$ \\
\hline 6-Fazer a diferença & $\begin{array}{l}\text { Construir a resiliência da } \\
\text { organização através da } \\
\text { cooperação com outras } \\
\text { organizações e comunidades locais } \\
\text { onde a organização opera. }\end{array}$ & $\begin{array}{l}\text { Colaborando: alinhando-se cm } \\
\text { outras organizaçõese } \\
\text { comunidades de mesma } \\
\text { mentalidade para beneficio e } \\
\text { suporte mútuo. }\end{array}$ \\
\hline 5-Coesão interna & $\begin{array}{l}\text { Melhorar a capacidade da } \\
\text { organização para a ação coletiva } \\
\text { alinhando as motivações dos } \\
\text { funcionários em torno de uma } \\
\text { visão inspiradora e um conjunto } \\
\text { de valores. }\end{array}$ & $\begin{array}{l}\text { Conectando: Criando uma cultura } \\
\text { internamente coesa, com alto } \\
\text { nivel de confiança que possibilite } \\
\text { que a organização cumpra seu } \\
\text { propósito. }\end{array}$ \\
\hline 4-Transformação & $\begin{array}{l}\text { Aumentar a inovação oferecendo } \\
\text { aos funcionários uma voz na } \\
\text { tomada de decisões e tornando-os } \\
\text { responsáveis pelo futuro delese } \\
\text { pelo sucesso geral da organização. }\end{array}$ & $\begin{array}{l}\text { Empoderando: Empoderando os } \\
\text { funcionários para que eles } \\
\text { participem da tomada de decisão } \\
\text { dando a eles liberdade e } \\
\text { autonomia. }\end{array}$ \\
\hline 3-Autoestima & $\begin{array}{l}\text { Estabelecer estruturas politicas, } \\
\text { procedimentose processos que } \\
\text { gerem ordeme aumentema } \\
\text { performance da organização, } \\
\text { criando um senso de orgulho do } \\
\text { funcionário. }\end{array}$ & $\begin{array}{l}\text { Desempenhando: Construindo } \\
\text { sistemas e processos de alta } \\
\text { performance que foquem na } \\
\text { gestão eficiente da organização. }\end{array}$ \\
\hline 2-Relacionamento & $\begin{array}{l}\text { Resolver conflitos e construir } \\
\text { relações harmoniosas que criem } \\
\text { um senso de lealdade entre os } \\
\text { funcionáriose uma conexão forte } \\
\text { com os clientes. }\end{array}$ & $\begin{array}{l}\text { Harmonizando: Criar um senso de } \\
\text { pertencimento e respeito mútuo } \\
\text { entre os funcionários e cuidar dos } \\
\text { clientes. }\end{array}$ \\
\hline 1-Sobrevivência & $\begin{array}{l}\text { Criar um ambiente de estabilidade } \\
\text { financeira, lucratividade e cuidar } \\
\text { da saúde e da segurança dos } \\
\text { funcionários. }\end{array}$ & $\begin{array}{l}\text { Sobrevivendo:Tornar-se } \\
\text { financeiramente viávele } \\
\text { independente. }\end{array}$ \\
\hline
\end{tabular}

Fonte: Barrett (2014)

Os desafios de desenvolvimento representam os estágios da organização, desde sua criação até o desempenho do espectro global.

O foco dos três primeiros níveis da consciência organizacional está nas necessidades básicas do negócio: estabilidade financeira e lucratividade, satisfação do cliente e do colaborador, assim como os sistemas e processos de alto desempenho.

O foco do quarto nível de consciência está na capacidade de adaptação: renovações e transformações contínuas, através da mudança das hierarquias rígidas, autoritárias e baseadas no medo, para sistema de governança inclusivo, adaptativo e com comunicação participativa e dialógica.

O foco dos três níveis mais altos de consciência está na coesão organizacional, na construção de alianças e parcerias mutuamente benéficas e em salvaguardar o bem-estar da sociedade humana.

Barrett (2014) afirma que as organizações que focam exclusivamente em suas necessidades básicas não são líderes de mercado, pois visam a questões internas, tornam-se 
rígidas e burocráticas para se inovarem em suas áreas de negócios. Sendo assim, a adaptação às mudanças impostas pelo mercado ocorre de forma lenta, e o nível de engajamento de seus funcionários é relativamente baixo, pois normalmente são gerenciadas por líderes autoritários e funcionam com base na cultura do medo.

Na prática, o desafio das organizações num ambiente impactado pelos paradoxos da globalização, pela valorização de informação e pela sociedade em rede, é encontrar o modelo de gestão que possa estar alinhado ao avanço tecnológico, portanto interconectado com o mundo e com possibilidade de captação e resposta aos estímulos em velocidades alinhadas.

Porquanto, faz-se necessário o entendimento de cada impacto, seja estrutural ou no perfil dos indivíduos que compõem seu quadro de colaboradores, e, evidentemente, a sociedade.

Nesse cenário, a gestão por valores reforça a estratégia da comunicação organizacional devido a sua característica dialógica, interpretativa, participativa e que efetivamente atende a esse novo universo em que se transformou a arena de negócios.

\section{A COMUNICAÇÃO ORGANIZACIONAL COMO ESTRATÉGIA NA GESTÃO POR VALORES}

O primeiro mercado a ser atingido é efetivamente o interno, então o processo de comunicação participativo e dialógico precisa ter como foco básico o cenário interior da organização.

Como cita Barrett (2014, p. 20), “O engajamento dos funcionários é uma medida do nível de engajamento intelectual e emocional que os mesmos têm como uma organização".

De maneira efetiva, a ação estratégica da comunicação organizacional na gestão por valores é permitir o engajamento do público interno e externo, através da disseminação estruturada da missão, da visão e dos valores da organização, permitindo ainda uma interação com outros interlocutores, numa dimensão politica, econômica, participativa, interdependente, flexível e adaptável às exigências da sociedade. (ROCCO, 2000).

Além desse elemento fundamentalmente básico, é necessário observar que todas as ações que compõem a estratégia são efetivamente elaboradas por pessoas, ou seja, pelo funcionário da organização, portanto existe a necessidade precípua de seu compromisso com os valores organizacionais e que podem ser colocados através do aprendizado.

O alinhamento desses propósitos e sua ressonância consistem em elementos de fundamental importância dentro das organizações inseridas na sociedade em rede.

De acordo com Kotler, Kartajaya e Setiawan (2010), outro destaque importante no processo de comunicação organizacional é que à medida que os consumidores vão se tornando mais colaborativos, culturais e espiritualizados, e o funcionário é o primeiro consumidor, ou seja, o consumidor interno, o caráter do próprio marketing se transforma.

Além desse aspecto, a organização passa cada vez mais a ser um conjunto de interações humanas com características de culturas que literalmente enxergam o mundo de maneira diferente.

Quando visualizamos o foco que se encontra mais elevado em termos de níveis de consciência, que está em satisfazer as necessidades da alma, isso inclui a necessidade de encontrar em nossas vidas a necessidade de fazer diferença e a necessidade de estar a serviço. Elas representam as nossas necessidades espirituais (BARRETT, 2014).

Basicamente, é o perfil desse funcionário, desse primeiro consumidor, dessa célula 
da sociedade que, além de suas necessidades pessoais materiais, pede a satisfação de suas necessidades emocionais e, sobretudo, espirituais.

Assim, as ansiedades e os desejos precisam ser identificados, almejando corações e mentes e, sobretudo, a espiritualidade.

De acordo com os autores Kotler, Kartajaya e Setiawan (2010), no paradoxo da globalização, a ansiedade e o desejo genéricos dos consumidores, para o denominado primeiro mercado - funcionários- consistem em transformar a sociedade - e o mundo - em um lugar melhor e talvez até mesmo ideal para se viver. Portanto, as empresas que pretendem ser ícones devem compartilhar do mesmo sonho com os consumidores e fazer diferença.

Nesse cenário o processo de comunicação organizacional tende a se adaptar para atender, dialogar, interpretar, pois hoje o funcionário, e, portanto, consumidor, busca algo além do que o dinheiro pode comprar, ou seja, busca significado, felicidade e realização espiritual.

Ainda afirmam os autores Kotler, Kartajaya e Setiawan (2010, p. 21), "A necessidade espiritual é o maior motivador da humanidade, que libera a mais profunda criatividade humana, sendo o modelo de negócio baseado em valores o que há de mais inovador".

Alinhar o funcionário, ou seja, o primeiro consumidor do primeiro mercado, que é o interno, dentro de uma estrutura harmoniosamente adaptada a um ambiente de sociedade em redes exige que o mesmo esteja literalmente engajado ou compromissado.

Sendo assim, a organização deve introduzir uma matriz baseada em valores em que num dos eixos, a empresa se esforce para ocupar mentes, corações e espíritos dos clientes atuais e futuros. Cabe destacar que os referidos clientes também englobam o quadro de funcionários da organização.

Figura 3: Matriz baseada em valores

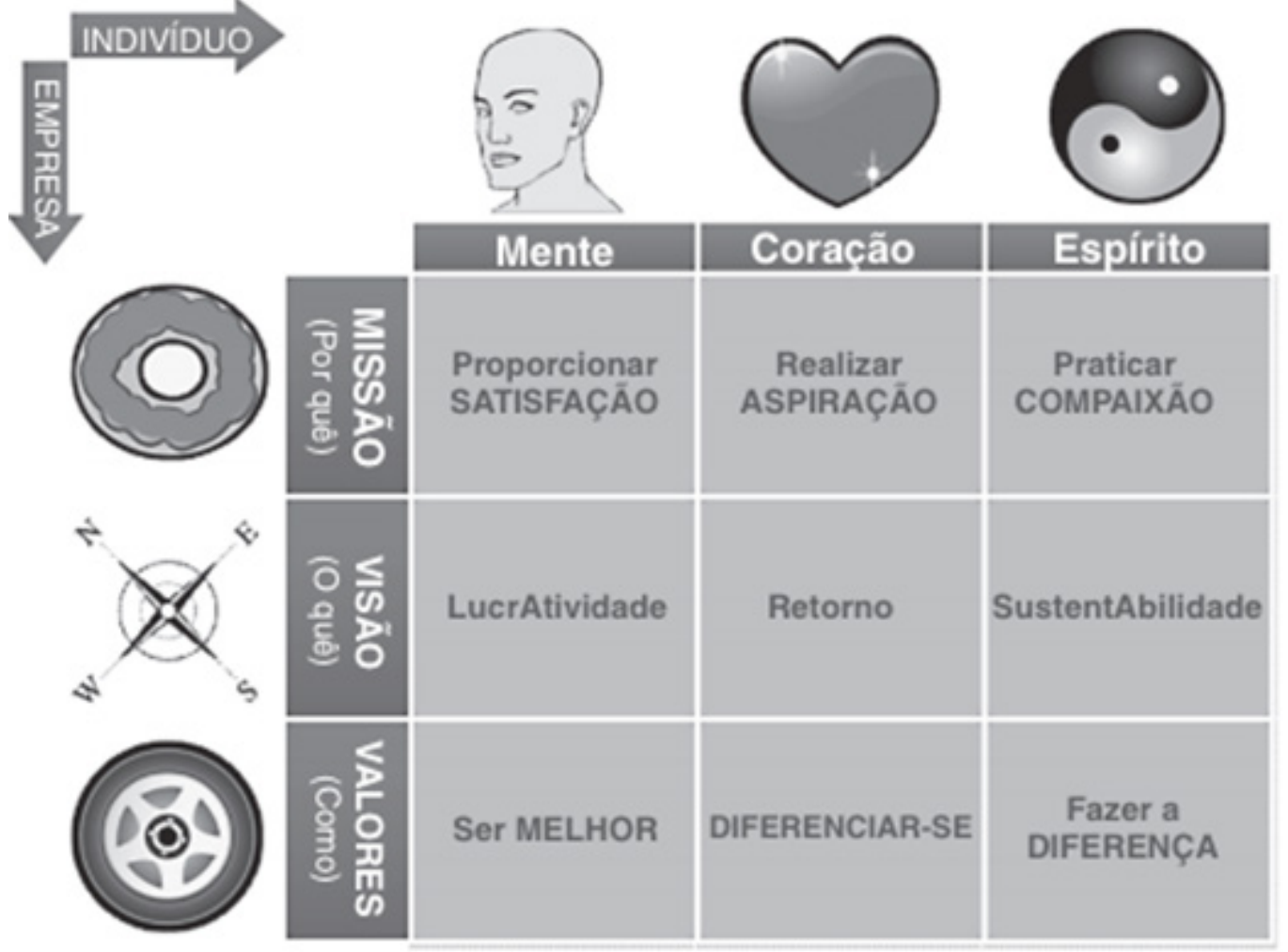


Cabe destacar que o estado ideal de uma organização remete a uma simetria de crença, intenção e entendimento sobre as relações de seus membros. "Na verdade, a assimetria de crença, intenção, relacionamento é o estado normal de uma organização. A organização é a luta para atingir a coorientação, não apenas um subproduto do mesmo". (TAYLOR; ROBICHAUD, 2004, p. 15).

Como explicam os autores, as pessoas precisam alinhar suas formas de lidar com o mundo objetivo e, simultaneamente, situar-se dentro de um mundo social. Se eles forem simplesmente engajados em ação, mas não são coorientados, eles não são organizados.

Cabe destacar que coorientação é negociação através do diálogo e tem como metas produzir coordenação de crenças, ações e emoções com algum objetivo mutuamente compreendido.

A coorientação não é um estado, mas uma atividade; não um produto, mas um processo. Por exemplo, diferentes opiniões sobre a liderança da organização não aparecem nas conversas que aconteceram durante o fim de semana, mas, sim, foram elaboradas pelas revelações e perspectivas discutidas pelos indivíduos, pois a opinião sobre determinado fato na organização não está isolada a um só funcionário.

Nesse contexto, a comunicação organizacional não se apresenta como uma mera fornecedora de informações, mas como elemento fundamental da coorientação e da disseminação interna e externa de valores, portanto com uma atuação estratégica de mudança e de gestão, sobretudo quando está voltada aos referidos valores através da Gestão por valores, pois se caracteriza como agente de motivação e comprometimento organizacional.

Como já citado, Genelot (2001) ainda afirma que a comunicação e a informação são instrumentos que são utilizados para desenvolvimento de uma cultura organizacional, abrangendo todos os participantes de maneira que se sintam envolvidos. Portanto, a comunicação organizacional não é um simples aditivo de uma estratégia organizacional, mas fundamento da arquitetura de uma estratégia comum.

Desta forma, os estudos da comunicação organizacional deixam clara a necessidade de seu emprego de forma estratégica e integrada pelas organizações para construção de valores compartilhados e de desenvolvimento de estratégias sustentáveis neste ambiente globalizado, interconectado e de sociedade em rede.

\section{PROCEDIMENTOS METODOLÓGICOS}

O estudo foi desenvolvido por meio de Pesquisa Qualitativa, de caráter exploratório e hermenêutico, tendo em vista o aprofundamento da base teórica através de bibliografia específica, artigos científicos publicados em revistas acadêmicas, dissertações de mestrado e teses de doutorado sobre os temas a serem discutidos: comunicação organizacional, gestão e valores.

O método adequado para os estudos de ciências humanas e sociais é aquele que permite a interpretação dessas relações, assim como a compreensão da dinâmica das partes e do todo, conhecido como círculo hermenêutico. 
As ciências humanas não podem ser modeladas através do método das ciências naturais, (...) que "truncam e mutilam a realidade histórica para assimilá-la aos conceitos e métodos das ciências naturais. Precisamos começar a investigação não com meras impressões sensoriais, mas com o ser humano inteiro, enquanto sentimento, vontade e pensamento.

(Dilthey 1991, apud Schimidt, 2012, p.55).

Através da análise crítica do material explorado, o objetivo é discutir a importância da comunicação organizacional, para o alinhamento dos valores da organização e do indivíduo, tendo como objetivo o comprometimento com a missão das organizações.

\section{CONSIDERAÇÕES FINAIS}

O objetivo deste trabalho foi desenvolver um estudo sobre a importância da comunicação organizacional como estratégia organizacional no ambiente globalizado baseado em valores.

A comunicação organizacional é identificada para um ambiente de grande complexidade, como um elemento de natureza objetiva, dialógica e participativa, integrante de um contexto de interatividade, decorrente da instalação da sociedade em rede.

O trabalho descreve os impactos dessas transformações no contexto da cultura organizacional e no alcance do indivíduo no quadro de funcionários da organização, destacando sua importância, como sendo o elemento base do primeiro mercado que é o constituído pelo público interno.

Além disso, analisa a mudança de perfil, legitimando os contextos empresariais, emocionais e espirituais envolvidos e destacados, na Gestão por Valores, destacando a importância do engajamento do funcionário e seu compromisso com a missão, a visão e os valores da organização, colocando a comunicação organizacional como elemento disseminador, bem como da coorientação fundamental para a consolidação do referido engajamento ou comprometimento.

Nesse contexto, a estratégia é constituída por ações organizacionais e só tem legitimidade através da comunicação. Assim, tem se o entendimento de que a comunicação organizacional se constitui na estratégia para o modelo de gestão, caracterizado pela gestão por valores, aplicado na organização inserida no ambiente globalizado. 


\section{BIBLIOGRAFIA}

BALDISSERA, R. A teoria da complexidade e novas perspectivas para os estudos da comunicação organizacional. In: KUNSCH, M.M.K. Comunicação organizacional: histórico, fundamentos e processos. São Paulo: Saraiva, 2009, pp.135-164.

BARRETT, R. A organização dirigida por valores: Liberando o potencial humano para a performance e a lucratividade. Tradução Caio Brisolla, Roberto Ziemer. Rio de Janeiro: Elsevier, 2014.

BAUMAN, Z. Globalização: As consequências humanas. Rio de Janeiro: Jorge Zahar, 1999.

BUCKINGHAM,M.; COFFMAN, C. Quebre todas as regras. Tradução de Ricardo Inojosa. Rio de Janeiro: Sextante, 2011.

BUENO, W. da C. A comunicação empresarial: definindo os contornos de um conceito. ConexãoComunicação e Cultura, Caxias do Sul, v.4, pp. 11-20, jan./jun. 2005.

BULIK, L. O paradigma da informação na era da globalização. 27-34. Revista FAMECOS mídia, cultura e tecnologia. Porto Alegre, n.5, dezembro, semestral 1996.

CARDOSO, O. de O. Comunicação empresarial versus comunicação organizacional: novos desafios teóricos. RAP, Rio de Janeiro, v.40, pp. 1123-1144, nov./dez.2006.

CASALI, A.M . Um modelo do processo de comunicação organizacional na perspectiva da Escola de Montreal. In: KUNSCH, M.M.K. Comunicação organizacional: histórico, fundamentos e processos. São Paulo: Saraiva, 2009.

CASTELLS, M. A sociedade em rede. A era da informação: economia, sociedade e cultura. 4 ed. São Paulo: Paz e Terra, 2000.

DENISON, D.R. Corporate culture and Organizational Effectiveness. NeW York: Wiley, 1990.

DIMAGGIO, P.J.; POWELL, W.W. (1983) Jaula de ferro revisitada: isoformismo institucional e racionalidade coletiva nos campos organizacionais. In. CALDAS, M.P; BERTERO, C.O. Teoria das Organizações. São Paulo: Atlas, 2007.

DOLAN, S. L; GARCIA.S. Gestão por valores. Rio de Janeiro: Qualitymark, 2006.

DUARTE, J.;MONTEIRO, G. Potencializando a comunicação nas organizações. In: KUNSCH, MMK. Comunicação organizacional: histórico, fundamentos e processos. São Paulo: Saraiva, 2009, pp.135164.

FONSECA, W.C Jr. A Comunicação Organizacional: um estudo epistemológico. 2007. 204f. Tese (Doutorado em Comunicação Social)- Universidade Metodista de São Paulo, São Bernardo do Campo. 
FREITAS, S.G. Comunicação, poder e cultura organizacional. Caderno de Pesquisas em Administração, São Paulo, 1999, pp.69-80.

GALLUP. State of Global Workplace Report. 2013. pp. 1-122. Disponível em: http://www.gallup. com/services/176735/state-global-workplace.aspx.Acesso em 08/01/2015

GENELOT, D. Manager danslacomplexité: reflexions à I"usagedesdirigents. 3 ed. Paris: Insep Consulting, 2001.

GOMES, L. O papel da comunicação nas aventuras da complexidade. Revista FAMECOS, Porto Alegre, n.34. dezembro/2007, quadrimestral.

GUEVARA, A.J.H. Consciência e Desenvolvimento Sustentável nas Organizações. São Paulo: Cengage Learning, 2008.

2013.

Da sociedade do conhecimento à sociedade da consciência, São Paulo: Saraiva,

GORDON, G.G.; DI TOMASO, N. Predicting corporate performance from organizational culture. Jornal of studies Management, v. 29,pp.783-798, nov. 1992.

KOTLER, P; KARTAJAYA, H; SETIAWAN, I Marketing 3.0: As forças que estão definindo o novo marketing centrado no ser humano. Tradução Ana Beatriz Rodrigues. São Paulo: Elsevier, 2010.

KUNSCH, M.M.K Relações publicas e modernidade, 2 ed. São Paulo: Summus, 1997.

Percursos paradigmáticos e avanços epistemológicos nos estudos da comunicação organizacional. Comunicação organizacional: histórico, fundamentos e processos. São Paulo: Saraiva: 2009.

Summus, 1986.

Planejamento de relações publicas na comunicação integrada. 3 ed. São Paulo:

LEVY, P. Cibercultura. 3 Ed. Tradução de Carlos Irineu da Costa. São Paulo: Ed. 34, 2010.

LEVITT, T. A imaginação de Marketing. Tradução de Auriphebo Berrance Simões. São Paulo: Atlas, 1991.

MARCHIORI, M.R Comunicação é Cultura. Cultura é Comunicação. In: Revista Comunicação Empresarial. São Paulo, n. 31, segundo trimestre, 1999.

MARCONDES, C.F Martin-Barbero, Conclini, Orozco. Os impasses de uma teoria de comunicação latino-americana. Revista Famecos, Porto Alegre, n.35. abril/2008, quadrimestral.

MARIN, A. L. Las nuevas sociedades informacionales. Madrid: Trotta, 2009. 
MASLOW, A. Motivation and personality. New York: Harper \& Brothers , 1954.

MCLUHAN, M. Cultura de massa. Tradução de Octavio Mendes Cajado, Ed. Cutrix, São Paulo: 1973.

MORIN, E; LE MOIGNE, J. L. A inteligência da complexidade. São Paulo: Peirópolis, 2000. Introdução ao pensamento complexo. 4 ed. Porto Alegre: Sulina, 2011.

PETERS, T.J; WATERMAN, R. H Jr. In search of excellence. New York: Harper e Row, 1982.

PUTNAM, L.; FAIRHURST,G. Discourse analysis in organization. In: JABLIN, F.; PUTNAM, L. The new handbook of organizational communication: advances in theory, research and methods. USA: Sage Publications, 2001, p. 78-136.

RESTREPO, J. M. Comunicación para la dinâmica organizacional. Signo y pensamento, Columnoa, v. 26. Universidad Javeriana: Facultad de Comunicación y Lenguage, 1995.

ROBBINS, S. Comportamento Organizacional. São Paulo: Prentice Hall, 2002.

ROCCO, A.J.J. A comunicação na era das organizações em rede: o falar e o escutar como ferramentas estratégicas de gestão. Dissertação de Mestrado. Pontifícia Universidade Católica de São Paulo, 2000.

SANTOS, N. M. B. F. Cultura e desempenho organizacional: um estudo empírico em empresas do setor têxtil. Revista de Administração Contemporânea. Rio de Janeiro, v. 2, n.1, pp. 47-66, jan/abr. 1998.

SCHALL, M.S. A communication-rules approach to organizational culture. Science Quaterly, n. 28, pp. 557-581, 1983.

SCHEIN, E. Guia de sobrevivência da cultura corporativa. Rio de Janeiro: Jose Olympio, 2001.

SCHIMIDT, L.K. Hermenêutica. São Paulo: Vozes, 2012.

SCROFERNEKER, C.M.A. Perspectivas teóricas da comunicação organizacional. GT Comunicação organizacional da Intercom, Brasil, v. 1, n. 31, 2000.

.Comunicação organizacional: certezas e incertezas. In: SCROFERNEKER, C. O diálogo possível: comunicação organizacional e paradigma da complexidade. Porto alegre: EDIPUCRS, 2008, pp.15-30

SENGE, P.M. A revolução decisiva. Rio de Janeiro: Campus, 2009.

SILVA FILHO, L. S. Valores pessoais e organizacionais: a busca do alinhamento, p. 79, Dissertação de Mestrado. Pontifícia Universidade Católica de São Paulo, 2014. 
SHANNON, C.E. \& WEAVER, W. Teoria Matemática da Comunicação. Tradução Orlando Agueda. São Paulo: Difel, 1975.

of America, 1949.

. The matematical theory of comunication. University of Illinois. United States

STOHL, C. Globalizing Organition Communication. In: JABLIN, F.; PUTNAM, L. The new handbook of organization communication: advances in theory, research and methods. USA: Sage Publication, 2001, pp. 78-136.

TAYLOR, J.R Da tecnologia na organização a organização na tecnologia. Revista Comunicação e Sociedade, Lisboa, v. 12, n. 1, 2008, pp. 83-102.

; ROBICHAUD, D. Finding the organization in the communication: discourse as action and sensemaking. Organization, v. 11, n.3, pp. 395-413, 2004.

TERRA, L. R. A comunicação organizacional no contexto das novas tecnologias e os desafios da complexidade: a contribuição da escola de Montreal para estratégia organizacional. Dissertação de Mestrado. Pontifícia Universidade Católica, 2012.

THOMPSON, E. P. Costumes em comum: estudos sobre a cultura popular tradicional. São Paulo: Companhia das Letras, 1998.

TORQUATO, G. Comunicação empresarial, comunicação institucional: conceitos, estratégias, sistemas, estruturas, planejamentos e técnicas. São Paulo: Summus, 1986.

, Tratado de Comunicação: Organizacional e Política. São Paulo: Pioneira Thomson Learning, 2002. 